NBSIR 78-1419

\title{
Life Test Development for Clothes Dryers
}

Julius Cohen

Institute for Applied Technology

National Bureau of Standards

Washington, D.C. 20234

Interim Report

October 1976 - September 1977

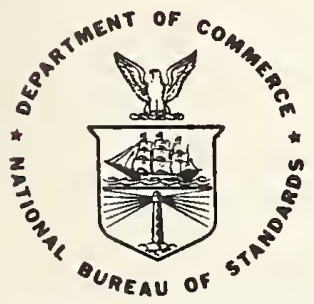

U.S. DEPARTMENT OF COMMERCE

NATIONAL BUREAU OF STANDARDS

100

.456

$78-1419$

c. 2 
Julius Cohen

Institute for Applied Technology

National Bureau of Standards

Washington, D.C. 20234

Interim Report

October 1976 - September 1977

U.S. DEPARTMENT OF COMMERCE, Juanita M. Kreps, Secretary

Dr. Sidney Harman, Under Secretary

Jordan J. Baruch, Assistant Secretary for Science and Technology

NATIONAL BUREAU OF STANDARDS, Ernest Ambler, Acting Director 
Table of Contents

Page

1. Introduction ... . . . . . . . . . . . . . . 1

2. Test Planning: Constraints \& Strategy . . . . . . . . . 1

2.1 Restatement of objective . . . . . . . . . . . 1

2.2 Sample selection . . . . . . . . . . . . . 2

2.3 Practical considerations . . . . . . . . . . . 2

2.4 Type of testing . . . . . . . . . . . . . . 2

2.5 Data sought . . . . . . . . . . . . . . 3

2.6 Performance criteria . . . . . . . . . . . 3

2.7 Use conditions . . . . . . . . . . . . . . . . 3

2.8 Energy efficiency . . . . . . . . . . . . . 4

2.9 Field testing .. . . . . . . . . . . . 5

2.10 Recording data . . . . . . . . . . . . . 5

3. Instrumentation . . . . . . . . . . . . . . 5

4. Experimental Procedure . . . . . . . . . . . . . 6

4.1 Performance . . . . . . . . . . . . . . 6

4.1 .1 Normal-weight load . . . . . . . . . 7

4.1 .2 Overload . . . . . . . . . . . . 7

4.1.3 Abrasive/impact load ........... . 8

4.1 .4 Monitoring .............. . 8

4.2 Energy efficiency . . . . . . . . . . . . . 8

4.3 Field testing . . . . . . . . . . . . . 8

5. Results . . . . . . . . . . . . . . . . 9

5.1 Performance . . . . . . . . . . . . . 9

5.2 Energy efficiency . . . . . . . . . . . . . 9

5.3 Field testing . . . . . . . . . . . . . 9

6. Discussion . . . . . . . . . . . . . . 9 9

Appendices

A. Comparison of components for various make dryers . . . . 11

B. Forms for reporting data . . . . . . . . . . . 12

LCP-1 Fallure report . . . . . . . . . . . . 13

LCP-2 Fallure analysis report . . . . . . . . . . 14

LCP-3 Field installation report . . . . . . . . . 15

LCP-4 Energy test for clothes dryer . . . . . . . 16

Acknowledgment . . . . . . . . . . . . . . . . . . . 17 


\section{List of Figures}

Figure 1. Circuit diagram of control box for automatically recycling dryers.

Figure 2. Dryer control panel equipped for automatic recycling -- make-A.

Figure 3. Close-up view of timer-advancer.

Figure 4. Dryer control panel equipped for automatic recycling -- make-B.

Figure 5. Make-A dryer equipped for squirting water onto loads. (Normally the door is closed; it is open here for illustration.)

Figure 6. Make-B dryer equipped for squirting water onto loads. (Normally the door is closed; it is open here for illustration.) 
1. Introduction

The objective of this ongoing work is to demonstrate the feasibility of developing standardized laboratory test methods for estimating useful life $\mathrm{e}^{*}$ and associated performance-based characteristics--e.g., failure modes** and reliabilities--of major appliances. Other performance testing work generally is made on components for an arbitrary duration of time, and a complete system may be tested for only a fraction of its expected life.

The electric clothes dryer has been chosen for initial work because of its relative electromechanical simplicity. The program is threefold: 1) laboratory test development; 2) energy efficiency testing; 3) controlled field testing. The emphasis of the work is on $1)$; 2) is an ancillary undertaking in which the time dependence of energy efficiency is being investigated; 3) is quite limited in extent, and is being done to elucidate field testing problems and methodology; it is not expected to yield definitive results. This publication reports on the progress of the program to date.

\section{Test Planning: Constraints \& Strategy}

The test planning, like all other aspects of the testing, is guided closely by a methodology formulated in anticipation of carrying out work such as this: product life testing. The highlights only of the test design are given in this section; for a detailed listing of procedural steps followed, see NBSIR 76-1157 (Chapter 12).

\subsection{Restatement of objective}

Different make clothes dryers have many superficial similarities, yet they are sufficiently different in design, materials, and construction to render a mixed sampling heterogeneous; (see, for example, Appendix A: Comparison of typical components for various make dryers). Thus, the primary objective of the present work can be restated specifically as the development of a standardized test method for estimating useful life and associated performance-based characteristics of a heterogeneous sampling of electric clothes dryers.

*Useful life is defined as the period of satisfactory reliability measured from the time the product is first put into service (for a discussion of this concept see NBSIR 76-1157). Admittedly it is subjective, but so is the concept of satisfactory performance, which must and is being dealt with.

Failure modes here means the prevailing, or most frequent failures. 
Owing to the heterogeneity, it is not possible to test the different makes identically, and this complicates test development. However, identicalness is not required. Standarized, or uniform, testing requires that different makes receive equivalent, unbiased treatment, with due regard to the prevailing use conditions of each.

\subsection{Sample selection}

The laboratory facilities available for this work limited testing to a maximum of 16 dryers. Rather than test one or two dryers of many makes -- the results would be of doubtful significance - 8 dryers each of the two most popular makes, representing over $50 \%$ of the home market, were chosen. Although lot sampling was used where feasible, the present sampling cannot strictly be considered random. Nevertheless, it may still be representative of the population at large.

Implementation of the adjunctive controlled field testing required that the dryers be limited to eight in number. All were chosen from a single make from the same lots which were to undergo laboratory testing. Half were placed in very high use situations, the other half in average use situations, for control.

\subsection{Practical considerations}

Clothes dryers are long-lived machines: their life expectancy is greater than $14 \mathrm{yrs}$. Obviously, laboratory testing must be completed within a small fraction of that (real) time.

The average-size household of four uses a dryer about 400 times (cycles) a year for -30 minutes per cycle. In the laboratory, the test cycles need to be run continually (a test cycle consists of a dryer on period, followed by an off period). Also, labor considerations generally require unattended operation for the major amount of time; i.e., other than the normal work hours. Intensive testing as outlined here can be implemented only if operation is substantially automated.

In summary, testing must be intensive (around-the-clock, if possible); machines must be automated for restarting and must be capable of running unattended for long durations. Notwithstanding, dryers are supposed to be maintained by frequent removal of lint from the filters. Accordingly this latter condition presents a challenge, as will be discussed subsequently.

\subsection{Type of testing}

Because no historical data regarding failure modes and times to failure were available, it was decided to simulate, as far as 
practicable in the laboratory, use in the horne. An attempt was made to keep the principal stresses normal so that failure modes and total use times would also be normal, thus providing a benchmark.

\subsection{Data sought}

Data sought for presentation at the conclusion of this project are:

- Test method specifications for (electric) clothes dryer life.

- Identification of factors which under - or overstress components.

- Years of equivalent life simulated in the laboratory.

- Description of maintenance actions.

- Numbers and types of failure; failure modes; times to failure; reliability; estimated useful life; repair actions.

- Tirne dependence of energy efficiency.

- Life of test load.

\subsection{Performance criteria}

The primary performance criterion is drying ability; i.e., the ability to remove moisture from a specified load within a specified time, satisfactorily.

A secondary criterion is that the load not be abnormally degraded, as determined by visual inspection, by the dryer per se; e.g., burn spots or abrasion.

Failure occurs if either criterion is not met.

\subsection{Use conditions}

Formulation of use conditions (including load) was aided by availability of extensive private-sector market research data. Three types of load are specified here:

1) a normal, or average-weight load;

2) a customarily-expected overload;

3) an abrasive/impact load. Table l, below, lists load compositions together with specified drying times and use 
frequencies in percent -- loads are expendable* and costing was a factor in selection.

Table 1. Load compositions, drying times, \& use frequencies

\begin{tabular}{|c|c|c|}
\hline Type of load & Drying time & $\begin{array}{c}\text { Use } \\
\text { frequency } \\
(\%)\end{array}$ \\
\hline normal-weight & 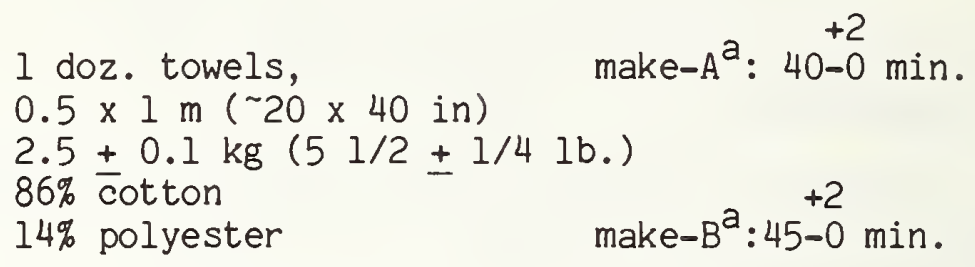 & 90 \\
\hline $\begin{array}{l}\text { customarily- } \\
\text { expected } \\
\text { overload }\end{array}$ & $\begin{array}{l}\text { double the normal } \\
\text { weight load, above }\end{array}$ & 5 \\
\hline abrasive/impact & $\begin{array}{l}1 \text { doz. metal buttons } \\
\text { riveted to } 0.33 \mathrm{~kg} / \mathrm{m}^{2}(10 \mathrm{oz} . / \mathrm{sq} \cdot \mathrm{yd}) \\
\text { cotton denim, } 0.6 \times 0.75 \mathrm{~m}(24 \times 30 \text { in) } \\
30 \pm 2 \mathrm{~min} \text {. (after folding in half and } \\
\text { hemming) }\end{array}$ & 5 \\
\hline
\end{tabular}

a The drying times for the two makes are required to be different. Additionally, the last 10 minutes of the drying cycle of make-A is run without heat, while for make-B, the last 5 minutes of the cycle is run without heat.

No data were available regarding environmental conditions of dryers in the field. In the laboratory, dryers were tested at whatever temperatures and relative humidities prevailed.

\subsection{Energy efficiency}

The time dependence of energy efficiency is to be investigated by making measurements on dryers as new, and periodically thereafter as they age. The Department of Energy Test** is being used because it is state-of-the-art.

*The survival time of towels against degradation by drying has been found to be $\sim 60$ hours.

** "Clothes Dryer Test Procedure", Federal Register, dated September 14, 1977, Vol. 42, No. 178, pg. 46145. 
Controlled-field testing will be used to monitor both performance and energy efficiency. In case of failure, repairs will be made by qualified (NBS) personnel. Energy efficiency will be measured shortly after installation and periodically thereafter at six month intervals.

\subsection{Recording data}

Forms were devised, preparatory to the experimental work, for the systematic and comprehensive recording of data. These are: 1) failure report, 2) failure analysis, 3) field installation, 4) energy test; and examples are given in Appendix B. 1) in particular is operational in the sense that it initiates a systematic course of action from the initial allegation of failure, to inspection, and finally to disposition or corrective action, if required; 2) is used for dryer failures other than early, where the cause is not readily discernable; 3) is used to identify the recipient, and to record safety test data; 4) is used for energy efficiency tests in the laboratory and in the field.

\section{Instrumentation}

Each dryer is instrumented with a cycle counter and an elapsed time meter to register total operating time. Dryers for the field have an additional elapsed time meter installed across the heater element for estimation of energy consumption.

In the laboratory, each dryer is equipped with a control box -- of which a circuit diagram is shown in figure 1 -- used in automatizing the following: 1) recycling of dryers; 2) rewetting of loads at the start of each drying cycle; and 3) discontinuation of recycling in tl!e event of water leaks (associated with dryer failure).

1) Figure 2 is a photograph of the control panel of dryer make-A, as equipped for automatic recycling. A motor mounted above the timer knob (left) advances the timer to the desired setting and a solenoid above the start button pushes down. Figure 3 is a more detailed view of the mechanism used to advance the timer. When activated by the control box, a one rpm electric motor turns the dryer timer knob through a mechanical coupling. The angular displacement, or time setting, is determined by means of an adjustable cam which actuates a microswitch to stop the motor. For the starting operation, a solenoid is used to depress a plunger which rests on the start push button.

Figure 4 is a photograph of the control panel of dryer make-B, as equipped for automatic recycling; the timer is at the right, and the start switch at the left. The automation instrumentation is similar to 
that used for make-A, except for starting, the solenoid is mechanically coupled to pull the start switch instead of pushing down.

2) Immediately after a dryer is started, a metered amount of water is squirted into the drum of the closed dryer, and onto the tumbling load of towels; thus, the load is fairly uniformly wetted. The water-squirting system consists in sequence of 1 ) an on-off rotary valve at the source; 2) filter; 3) main line solenoid valve (normally energized to remain open); 4) pressure regulator; 5) pressure gauge; and 6 ) water pipe to the dryers. Coming off the water pipe at each dryer station is a solenoid valve coupled to a flexible length of plastic tubing, connected in turn at the dryer, to a small copper tubing (nominal 1/8" o.d., 0.030" wall thickness). The amount of water dispensed is a function of the water pressure, pipe dimensions, and time. The pressure is held constant by means of the regulator so that the quantity of water is adjusted by regulating the time.

Figures 5 and 6 show respectively, makes $A$ and $B$ equipped for squirting. (Normally doors are closed; they are opened here for illustration.) For make-A, the tubing enters at the bottom (for ease of installation); approaches, but does not extend to the rim of the drum; and is directed to squirt upwards and to the right into the tumbling load. The copper tubing is terminated with neoprene tubing to prevent possible load damage. For make-B, on the other hand, the tubing enters at the top and is directed to squirt downward and to the right into the drum. (A prior arrangement similiar to that used for make-A was found to be unsatisfactory because water from the squirt tube would be deflected by the tumbling load into the lint filter and blower assembly, as well as out the door.)

3) Under each dryer, at a strategic location for early warning, is fastened a small pan containing a water sensor. In case of leaks due to dryer failure, the sensor will signal the control box not to restart the affected dryer (the dryer cycle in progress, however, will run to completion).

In the event of leaks due to solenoid valve failures at the dryers, additional sensors positioned near the front of each dryer will activate an independent control box, thus closing the main solenoid valve to the water supply. The dryers will continue to recycle, but with unwetted loads.

4. Experimental Procedure

\subsection{Performance}

Compositions of the various type loads, together with their drying-time settings and use frequencies have been given in Sect. 2.7. An abridged procedure for running these loads is given 
below; all tests are made with dryer temperature set at HIGH, or NORMAL.

\subsubsection{Normal-weight load}

For attended operation normal-weight loads are placed in each of 16 dryers; clean lint filters are installed, and the on-off switches of the individual dryer control boxes and the master timer are turned ON. Groups of four dryers each will be activated sequentially and automatically at 15 minute intervals, and will be recycled every 60 minutes thereafter. At activation, first the dryer timer is rotated to the prescribed setting, then the machine is started and simultaneously a metered amount of water, 75$80 \%$ by weight relative to the nominal weight of the dry load, is ejected for approximately two minutes onto the tumbling load for uniform wetting. At the completion of the drying cycle the machine turns off for 15 or 20 minutes, depending on make, until being automatically restarted. The attendant frequently cleans the lint filters.

Owing to design differences it is found necessary to use different methods for running the different makes unattended for long times. For make-A, (clean) filters may be left in the machine overnight; for weekend runs, the filters are removed and the lint collected in a filter external to the machine. For make-B, a special auxiliary filter, developed for this work, is installed in the normal air stream to extend the filtering capacity sufficiently to rur the dryers overnight -- it is essential, however, that the towels not be new or old, as these are very prolific generators of lint. At present it is not feasible to run make-B dryers weekends -- attempts to run with the filter removed were unsuccessful -- and developrient work to meet such an objective is continuing.

\subsubsection{Overload}

Running the custornarily-expected overloads requires operator action. Two dozen towels, or double the normalweight load, are placed in the dryers, and the amoun $\mathrm{t}$ of water to be dispensed may be doubled also by resetting the timer on the individual control boxes to twice that used for the nornal-weight, load. As before, control boxes and master timer are switched ON; when machines start automatically, the operator advances the timers to 70 minutes (this obviates cool-down). Recycling will occur every 60 minutes. 
The special test cloths are thoroughly wetted in a clothes washer (new cloths are first washed twice with detergent and thoroughly rinsed, to remove sizing), and spin dried to completion of the spin cycle. One test cloth is placed in each dryer, and the control box switches are turned OFF to disengage the automatic restart system. The operator sets the dryer timer and pushes the start button.

\subsubsection{Monitoring}

Several times each day, dryness of the loads is monitored tactually*, soon after the drying cycles are completed. In case of failure, repairs are carried out, repair data are recorded, and the unit is restored to test.

Drum linings are visually inspected after running impact/abrasive loads, for signs of degradation.

\subsection{Energy efficiency}

For measurements of energy efficiency the test procedure previously cited, is being used. Thirty-three pieces of special test cloth of $50 \%$ cotton - 50\% polyester composition are spin dried in a washer, then tumble dried in a dryer, both to prescribed tolerances of moisture content. For procedural details see the test procedure cited; for details of the quantities measured, as well as the method for calculating energy efficiency, see Form LCP-4, Energy Test, in the Appendix to this report. The tests are being carried out periodically in the laboratory with different small samplings each time, and in the field.

\subsection{Field testing}

Dryers are checked for safety 1) in the laboratory, after being instrumentated and, 2) in the field, after being installed; for details see Form LCP-3, Field Installation Report, in the Appendix. Subsequently, qualified laboratory personnel carry out periodic energy efficiency tests, and make repairs when necessary.

*For better reproducibility, it is planned to replace this subjective determination by one based on weighing. 


\subsection{Performance}

Laboratory testing began, for all practical purposes, some six months ago, and since then, make-A dryers have logged six years of equivalent life* and make-B, four years of equivalent life. There have been three bona-fide dryer failures: one early, and two random, all with make-A. Failed components were a timer, a timer knob, and a heater element.

\subsection{Energy efficiency}

Thus far, energy efficiencies measured in the laboratory show little or no change with simulated age of dryers. The value is roughly $1 \mathrm{~kg}\left(\mathrm{H}_{2} \mathrm{O}\right) / \mathrm{ksh}$, with make- $\mathrm{B}$ appearing slightly more efficient.

\subsection{Field testing}

Dryers were placed in the field about five months ago, and there have been no reports of failure. Energy efficiencies measured shortly after installation were similar to those measured in the laboratory before installation.

\section{Discussion}

The reliability of the dryers so far has been high, as was expected for an established and slowly evolving product. The dryers are now in their random failure period of life where reliability is maximurn, and appreciable failures are not expected until well into life, when parts wear out.

On the other hand, the autonation system, new and untried, required considerable debugging. Most problems appear to have been corrected with the exception of the water injection system: leaks or flooding occurs frequently owing to malfunctioning solenoid valves. The primary cause of failures, however, appears to be the water supply itself, or specifically, the mineral salts dissolved therein. These precipitate in the pipe, then migrate as particles to the solenoid valves and prevent complete closure. Corrective action will be attempted: it is planned to install a water softener, and to use another kind of valve which may be less sensitive to debris.

An important finding has been made already in field testing. At one site the initial energy efficiency measured was about $20 \% 1$ ower than expected. Investigation showed the existent ductwork to have been improperly installed; this led eventually to substantial accumulation of trapped lint, and as a consequence, appreciable decrease in air flow. Cleaning the lint from inside the ductwork restored energy

*Based on 416 cycles per year. In the laboratory work the average duration of a cycle is $40 \mathrm{~min}$., in the field it is a $30 \mathrm{~min}$., and the difference is due to the types of load. 
efficiency to a normal value. Improperly installed ductwork can lead to decreased energy efficiency and higher operating costs, as well as failure to dry.

A reminder: This is a test development project being made from scratch and modifications in procedure and instrumentation may be expected before its completion. 


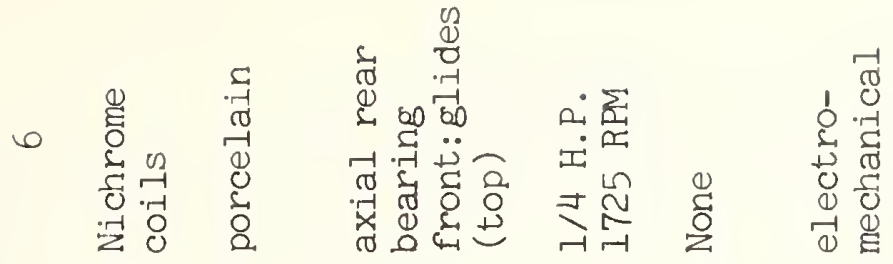

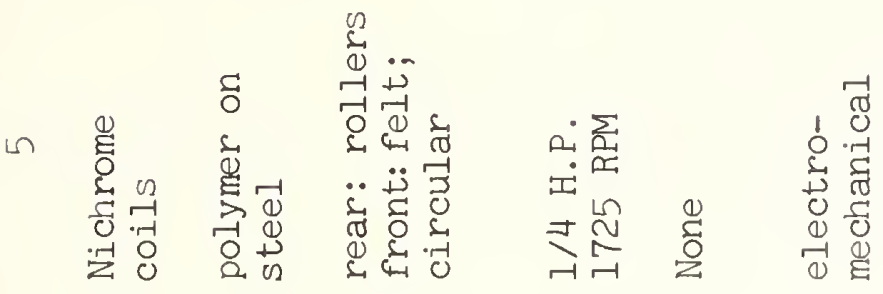

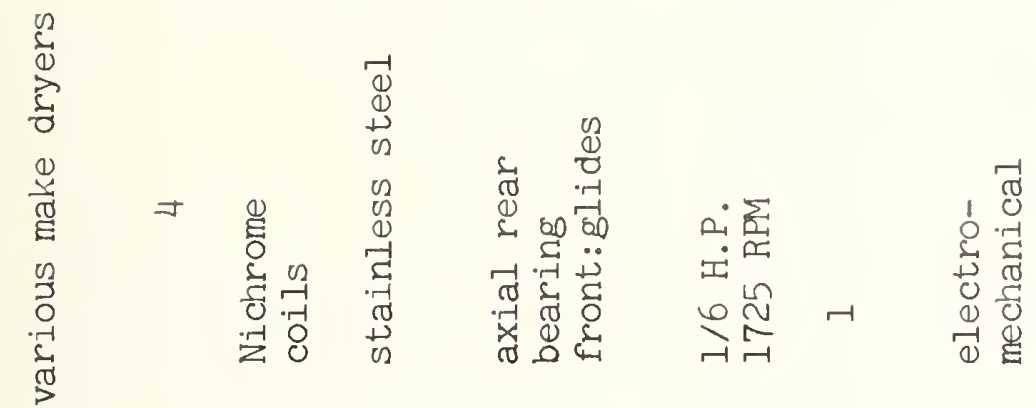

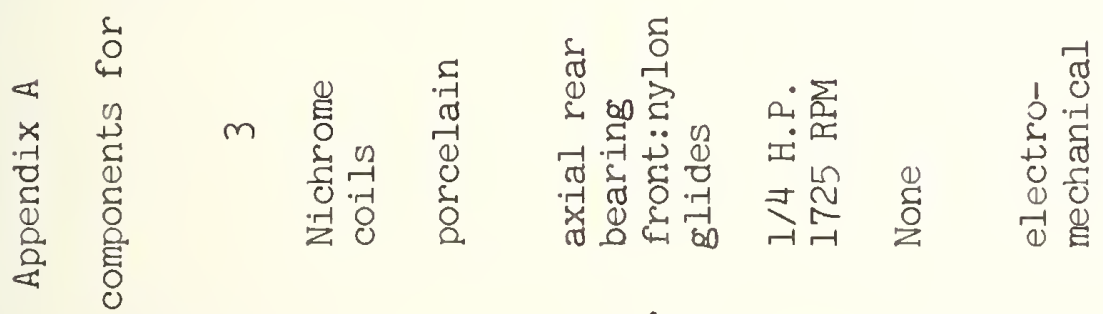

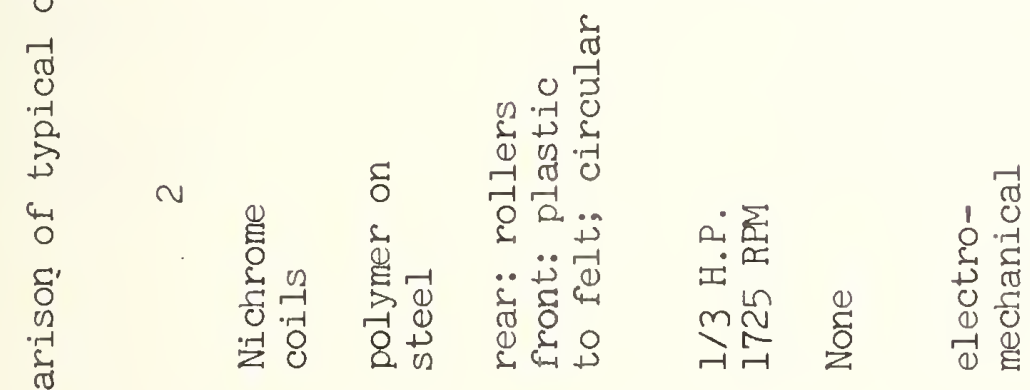

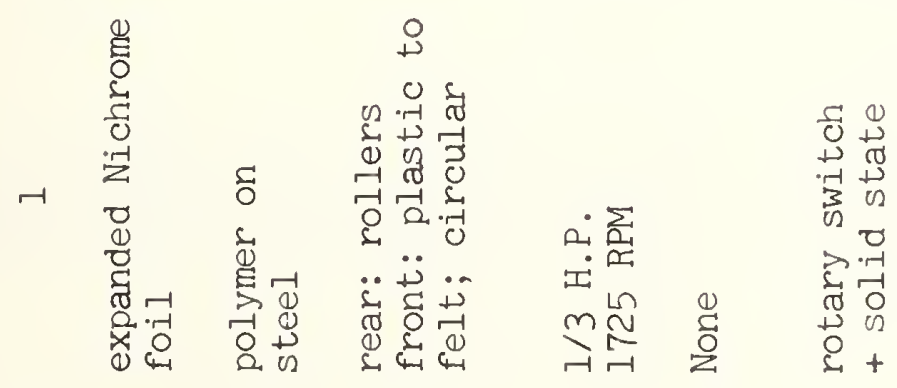

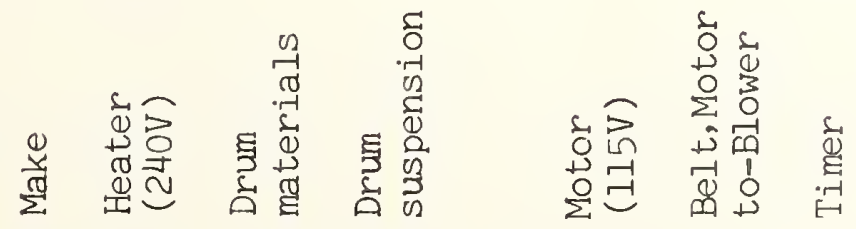


Appendix B

Forms for reporting data

LCP-1 Failure report

LCP-2 Failure analysis report

LCP-3 Field installation report

LCP-4 Energy test for clothes dryer 
1. No.

2. System

5. Unit

A. Inoperative

B. Intermittent

C. other
3. Ident.

6. Unit oper. time

A. Hr. elapsed

B. Cyele no.
4. Environinental

A. Lab

B. Field

7. Symptoms

8. Originator

Ext.

9. Date

10. Tests performed, results, comments

11. Confirnation
$\wedge$.
Yes
B.
110

12. Causes
A.
Defective part
D. Sccondary
B. Testing error
E. other
C. Primary

13. Analysis required 14. Part operating time to failure
A. Yes
B. No

15. Cognizant engineer

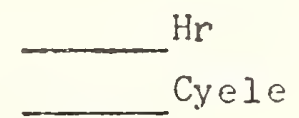

;Ext .
16. Date

16. Describe eorrective action taken (list parts replaeed, part nos.)

17. Aetive repain time hr 18. Rerairman 19. Dàtc 20. Daie returned to test. 21. Aszociated fajlure roport: 


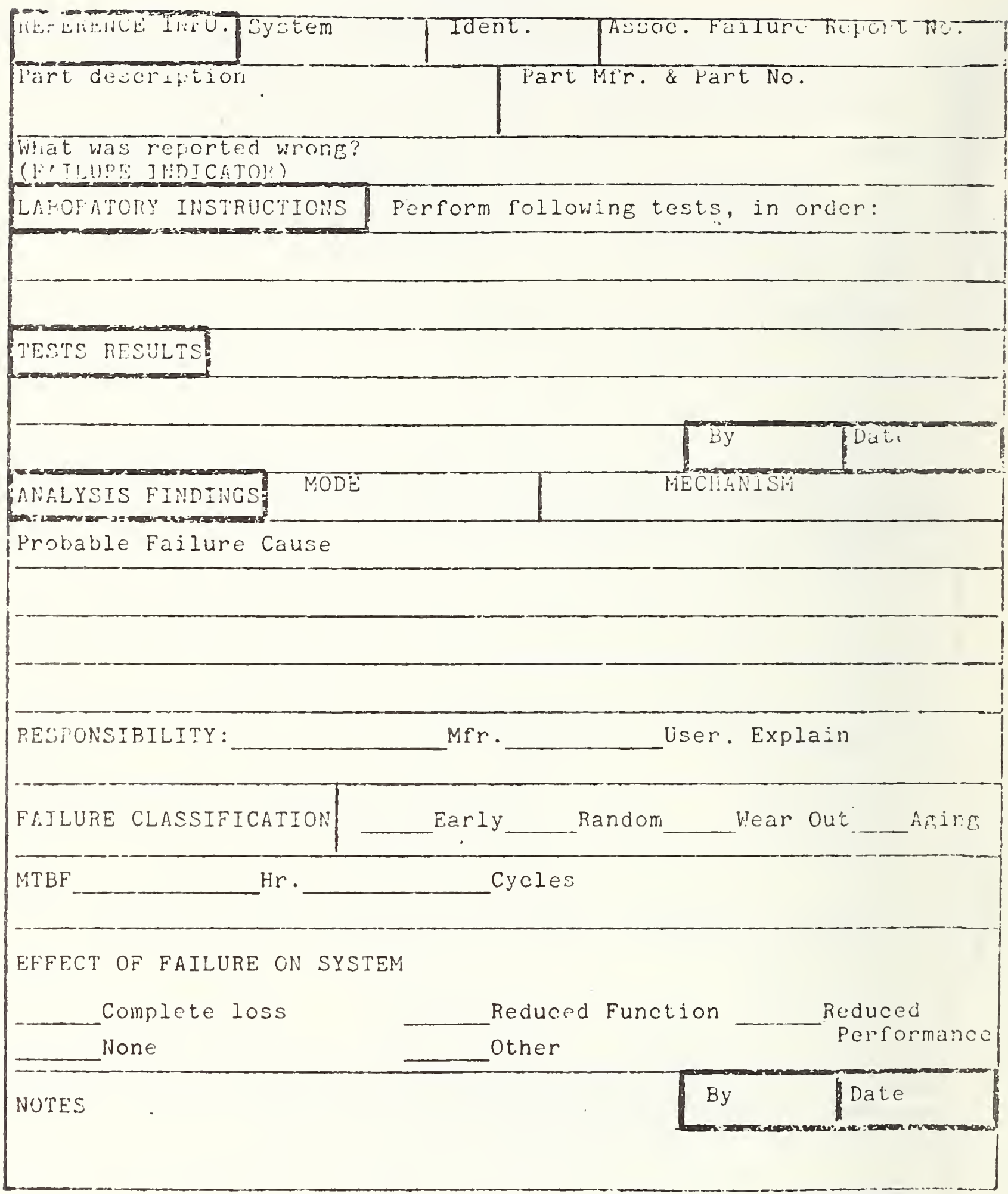


FIELD INSTALLATION REPORT

Code No.

Z

1. System clothes dryer

2. Make \& Serial No.

3. Location of site

4. Responsible person

Tel.

FIELD INSTALLATION REPORT

Code No.

System clothes dryer

5. Dielectric strength Acceptable Not acceptable

6. Leakage currents (worst case)

A. Appliance cold (before running) ma

B. Appliance hot (after running) ma Acceptable Not acceptable. Explain

7. Tested by

Ext.

8. Date

8. Safety tests

A. Visual inspection of site wiring Adequate Inadequate

B. Leakage currents on site

1) appliance cold ma

2) appliance hot ma Acceptable Not acceptable. Explain

9. Initial cycles 10. Initial elapsed time
A. Heater hr
B. Motor hr

10. Date installed 11. By Ext. 
ENERGY TEST FOR CLOTHES DRYER

1. Sitc:
A.
Lab .
Bldg . Identification

B . Field

Code No.

2. Environmental (for field use only)

A. Location (kitchen, laundry room, basement, other)

B. Conditioning (heated, air conditioned, ncither)

C. Type of dwelling (private res., apt. bldg., other)

3. History
A. Elapsed time: Heater hr; Motor hr. B. Cycles

4. A. Load B. Rinsc water temp.

5. Weights

6. Energy

A. Bone dry $\mathrm{kg}$

A. Initial

B. After

C. After $\mathrm{kg}$ min.)

D. Heat dry (additional $\mathrm{kg}$ min.)

B. Spin dry $\mathrm{kg}$

C. Heat

8. Observer ;Ext .

7. Ambient

min

kWh

A. Dry bulb_ ${ }^{\circ} \mathrm{F}$ min. kwh

B. Wet bulb_ ${ }^{\circ} \mathrm{F}$ kWh

C. $\because \mathrm{RH}$

1.0. Computation

A. DoE

1) Moisture removed $=5 \mathrm{~B}-5 \mathrm{C}=$ $\mathrm{kg}$

2) Energy used $=6 \mathrm{~B}-6 \mathrm{~A}=$ kWh

3) Efficiency $=\frac{\text { Moisture removed }}{\text { Energy used }}=$ 9. Date

B. Modificd

1) Moisturc removed $=5 \mathrm{~B}-5 \mathrm{D}=$ $\mathrm{kg}$

2) Energy used $=6 C-6 \Lambda=$ kWh

3) Efficiency $=\frac{\text { Moisture removed }}{\text { Energy }}=$ $\frac{\mathrm{kg}}{\mathrm{kwh}}$ 
Acknowledgment

Thanks are due Owen Laug for designing the automating instrumentation. 


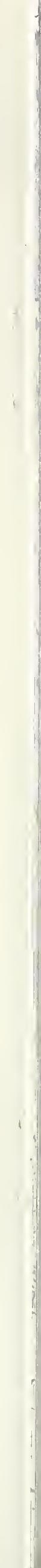




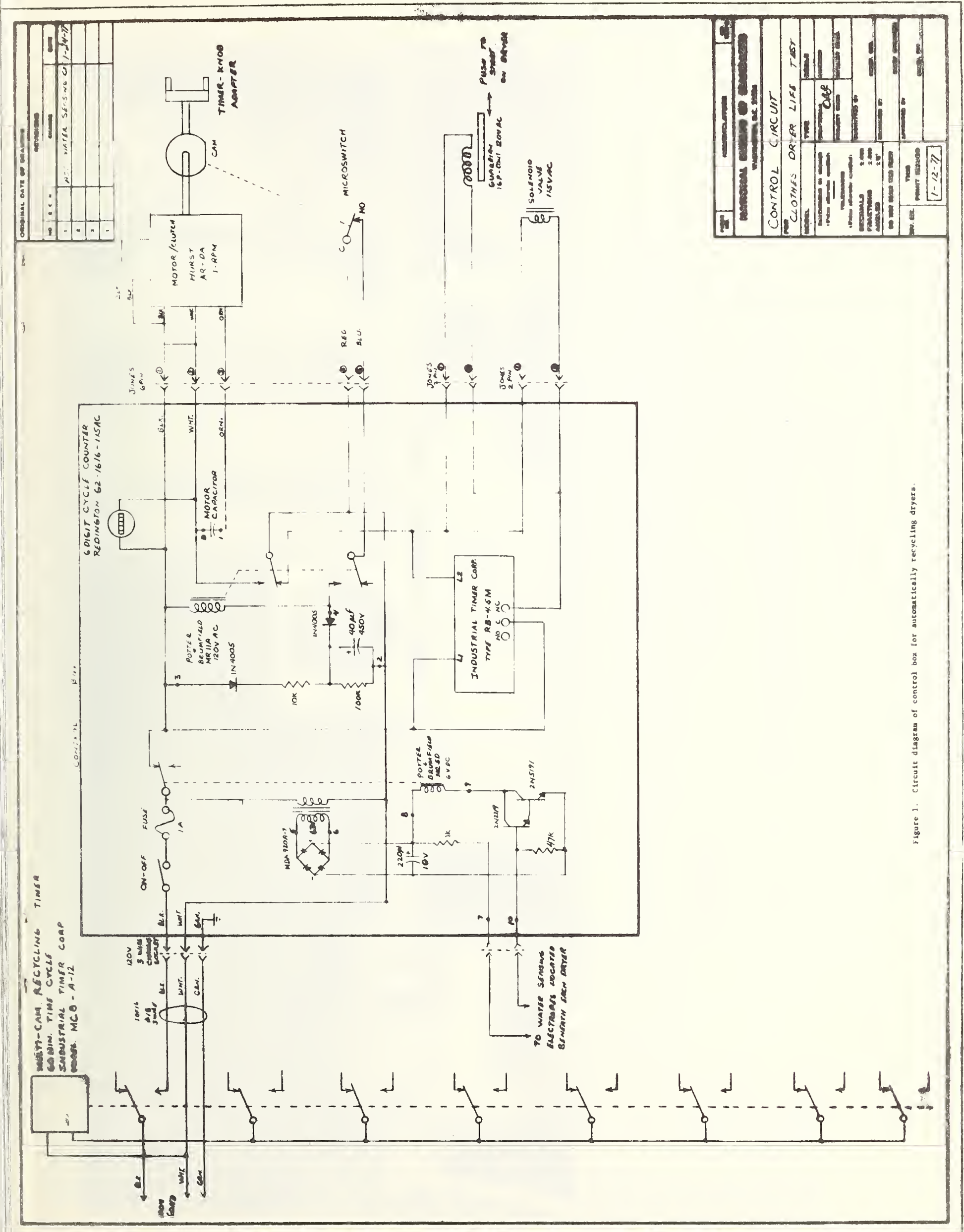





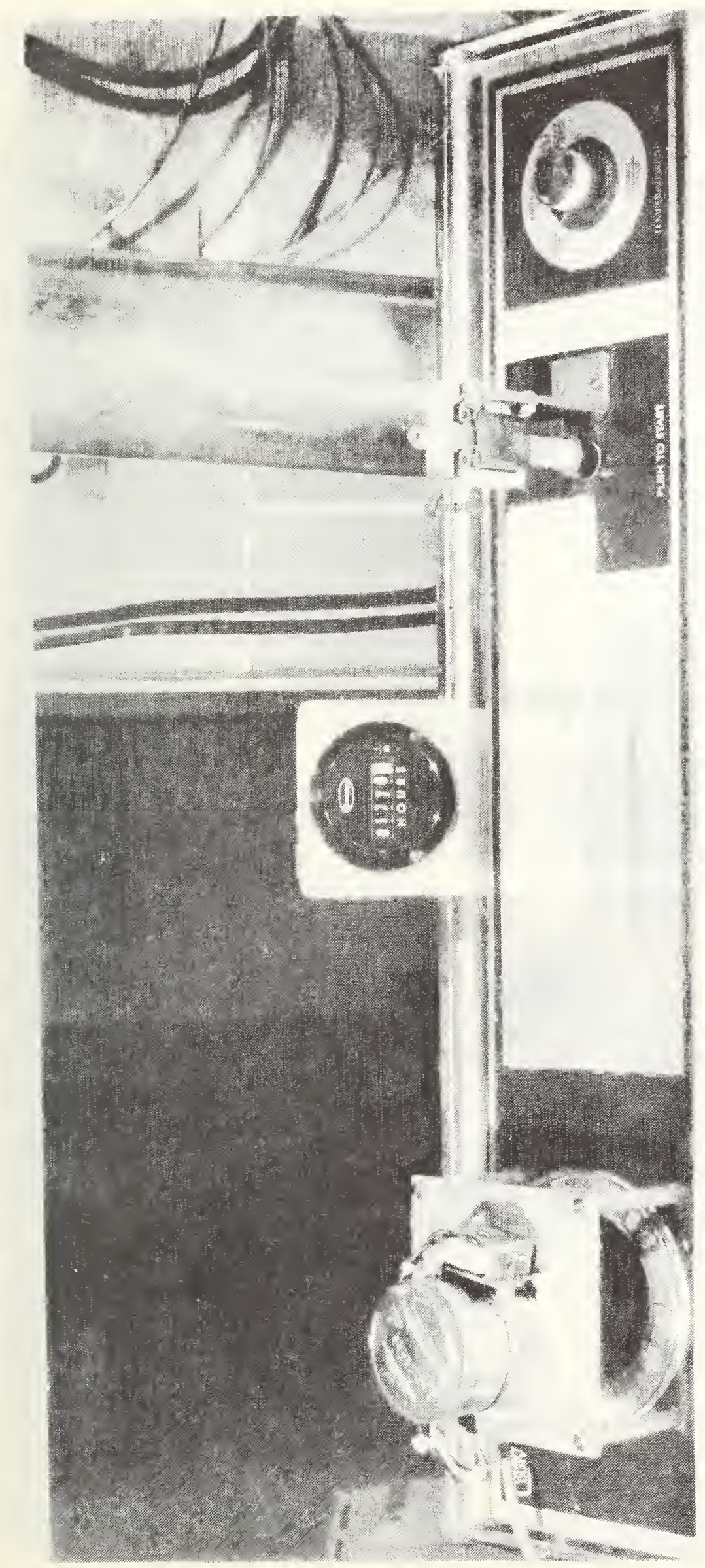

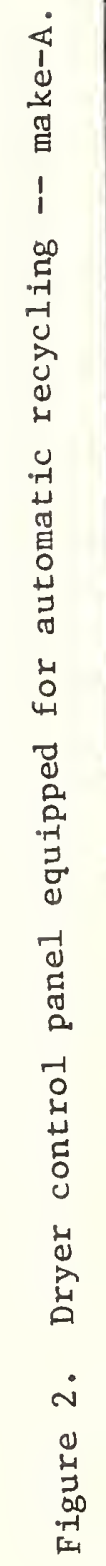






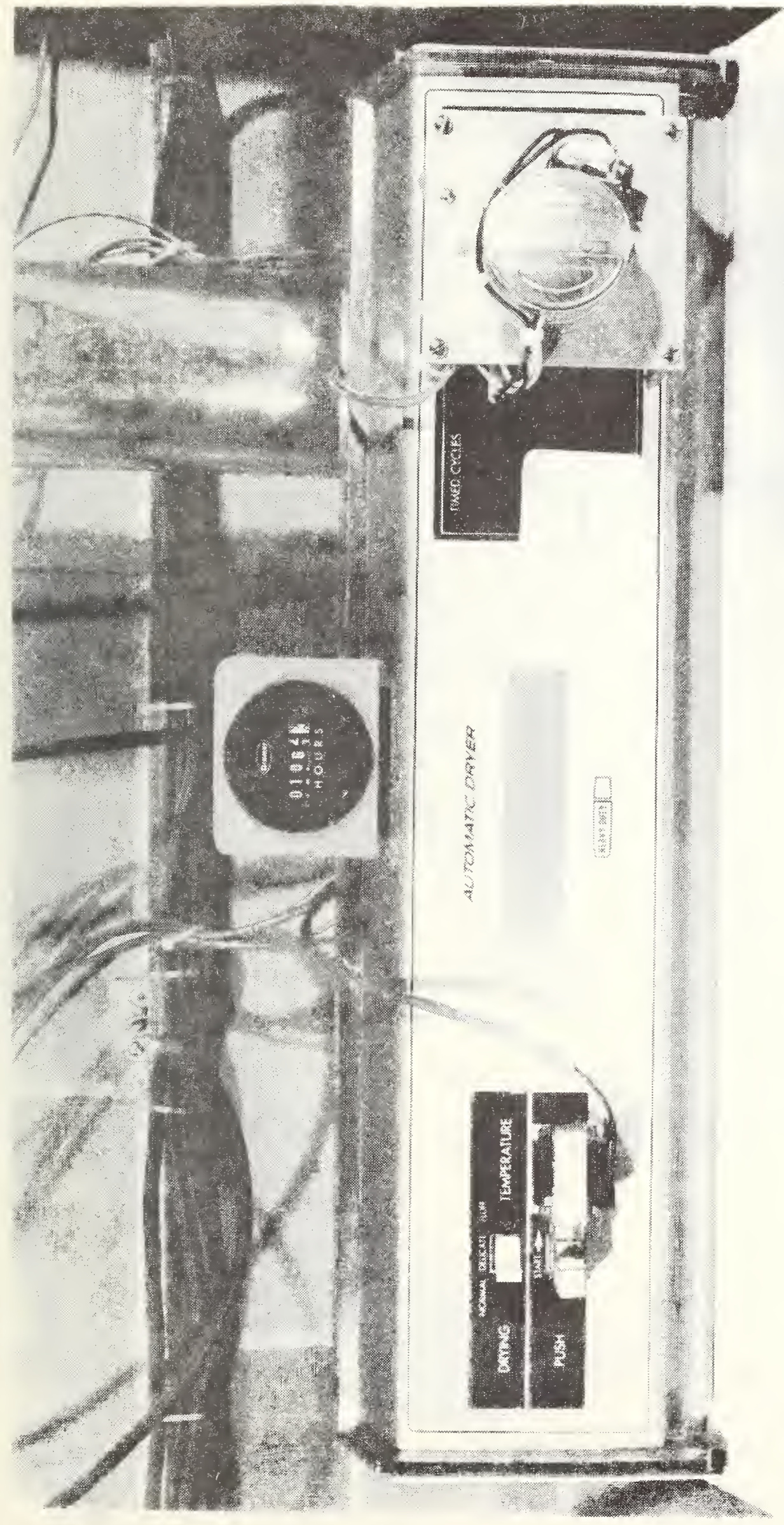

章

告

.

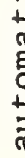

언

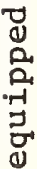

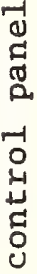

림

-

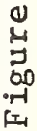




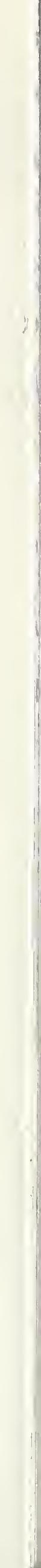




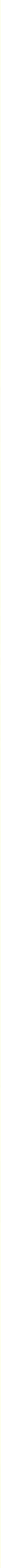



NBS.IIAA IREV , ,

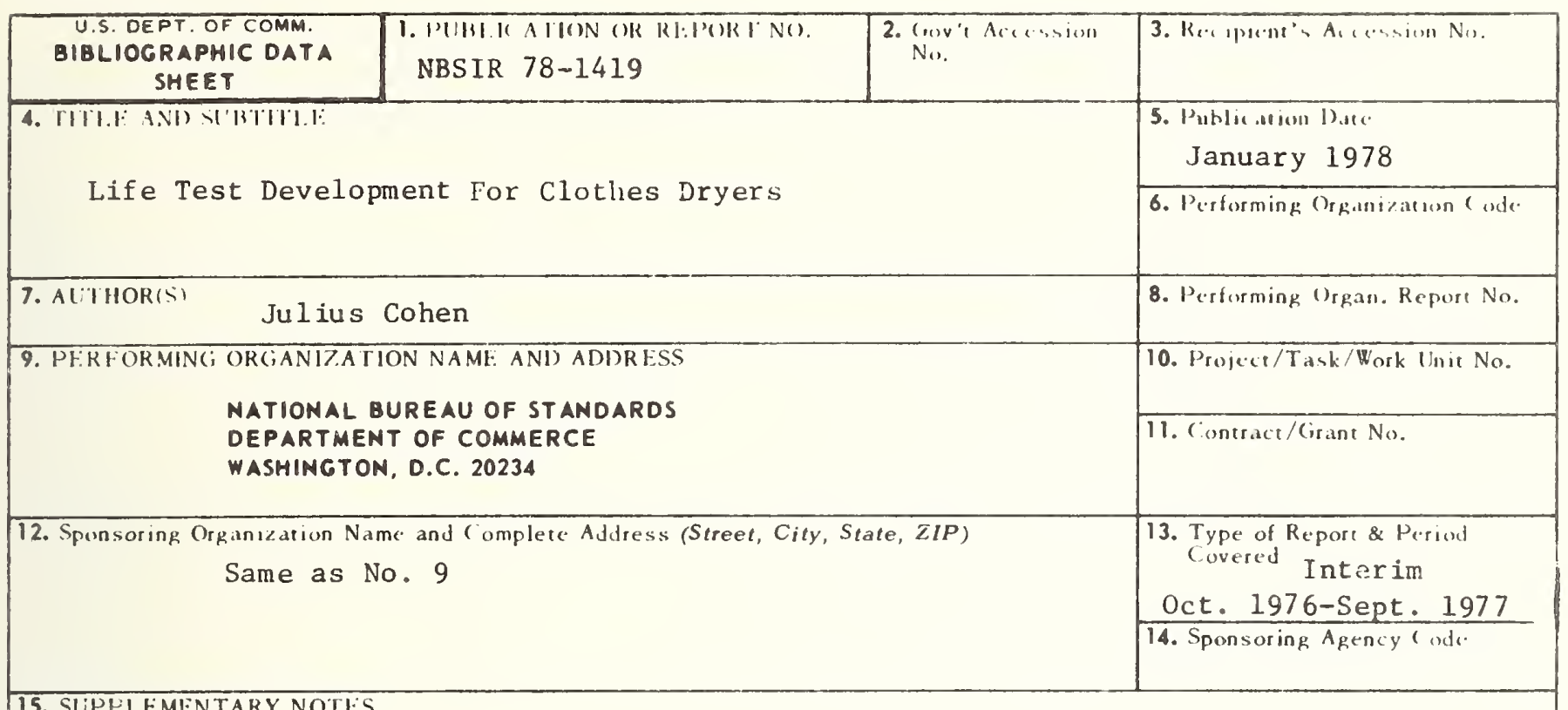

15. SLIPFI.FMIENTARY NOTIS

16. AlBSTRAC T (A 200-word or less factual summary of most significant information. If document includes a significant bibliography or literature survey, mention it here.)

This interim report deals mainly with development of a life test for electric clothes dryers. The testing is being guided by a previously formulated methodology, and highlights of the test planning process are given. Testing is intensive, and up to seven years of life have been simulated in the laboratory. As expected for a long-lived product, there have been only a few dryer failures so far. Additionally, the temporal dependence of energy efficiency is being investigated.

17. KI:Y W(ORIST (six to twelve entress; alphabetical order; captidize only the frsst letter of the first key word unless a proper nome; separated by semicolons)

Clothes dryer; energy efficiency; life test; performance; reliability engineering

18. AVAll.AlsIITY Unlimiled

X Dor (Offecial Distributom. Ho No Release fo Nols

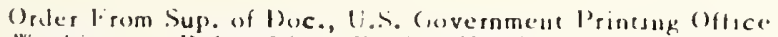
Washingron, 1).( . 20102, il) ( all. No. (13

Order from National Technical Information Service (NTTS Springfield, Virganial 22Is

\begin{tabular}{|c|c|}
\hline $\begin{array}{l}\text { 19. SI:( URITY (I.ASS } \\
\text { (IIIS RIIPURT) } \\
\text { IIN( I. ASSIIIII) }\end{array}$ & 21. NO. OF PACFE \\
\hline $\begin{array}{l}\text { 20. SIOC URITY ( I.ASS } \\
\text { (1HIS BA(,E) }\end{array}$ & 22. I'rice. \\
\hline UN( 1.A.S.TH11:1) & \\
\hline
\end{tabular}


1 
